\title{
Spiritual and religious aspects of skin and skin disorders
}

This article was published in the following Dove Press journal:

Psychology Research and Behavior Management

2 August 2014

Number of times this article has been viewed

\section{Philip D Shenefelt' \\ Debrah A Shenefelt ${ }^{2}$ \\ 'Dermatology and Cutaneous Surgery, University of South Florida, Tampa, \\ ${ }^{2}$ Congregation Or Ahavah, Lutz, \\ FL, USA}

Correspondence: Philip D Shenefelt Dermatology and Cutaneous Surgery MDC 79, University of South Florida, I290| Bruce B Downs Blvd, Tampa,

FL 33612, USA

Tel +l 8I39744270

$\mathrm{Fax}+\mathrm{I} 8139744272$

Email pshenefe@health.usf.edu

\begin{abstract}
Skin and skin disorders have had spiritual aspects since ancient times. Skin, hair, and nails are visible to self and others, and touchable by self and others. The skin is a major sensory organ. Skin also expresses emotions detectable by others through pallor, coldness, "goose bumps", redness, warmth, or sweating. Spiritual and religious significances of skin are revealed through how much of the skin has been and continues to be covered with what types of coverings, scalp and beard hair cutting, shaving and styling, skin, nail, and hair coloring and decorating, tattooing, and intentional scarring of skin. Persons with visible skin disorders have often been stigmatized or even treated as outcasts. Shamans and other spiritual and religious healers have brought about healing of skin disorders through spiritual means. Spiritual and religious interactions with various skin disorders such as psoriasis, leprosy, and vitiligo are discussed. Religious aspects of skin and skin diseases are evaluated for several major religions, with a special focus on Judaism, both conventional and kabbalistic.
\end{abstract}

Keywords: skin, skin disorders, spiritual, religious

\section{Spiritual and religious aspects of skin and skin disorders}

Skin and skin disorders have had spiritual and religious aspects since ancient times. The shamans who helped our ancestors to survive and who even today in many areas of the world help to treat skin disorders in part through spiritual means believed that negative spiritual effects could help produce illness and that positive spiritual effects could help alleviate illness. The shamans often employed trance-like states known as altered states of consciousness (ASC) to access the spiritual. There is much still to be learned from the time-tested shamanic approach to the spiritual through ASC. Spiritual effects on skin, skin disorders, and healing of skin disorders occur through mechanisms that medical science is just beginning to understand.

Psychoneuroimmunology of the skin is elucidating how the mind can influence the skin and skin disorders. ${ }^{1}$ The modern Western approach to ASC through hypnosis can be used to produce significant improvement or resolution of many skin disorders. ${ }^{2}$ As Dr David Spiegel ${ }^{3}$ has said, "It is not all mind over matter, but mind matters". Spirit, mind, emotions, and body are one holistic unit and each aspect influences skin, skin disorders, and healing. In this paper the focus will be on how spiritual experiences, often in ASC, and religious beliefs, rituals, and prayers can affect various aspects of skin and skin disorders. Several relevant topics will be discussed to help clarify how such spiritual and religious effects on skin and skin disorders can occur. 


\section{Methods}

Online searches were conducted in September and October 2013 in Scopus and in Medline/PubMed extending back as far as the data base would allow, into the 1960s. Searches were performed with various combinations of terms, ie, "spiritual", "religious", "skin", and "skin disease", as well as names of common skin diseases including "acne", "eczema", "dermatitis", "leprosy", and "psoriasis". Other references were obtained from the papers and book chapters as well as books located through the search process. Bookfinder.com was also searched for relevant titles. Classical commentary by Biblical scholars was also included. ${ }^{4-6}$

\section{Spirituality and spiritual healing as it relates to skin}

Numerous definitions of spirituality exist. According to Philip Sheldrake, spirituality is centered on the "deepest values and meanings by which people live". ${ }^{4}$ Del Rio and White define spirituality as "an attitude toward life, making sense of life, relating to others, and seeking unity with the transcendent" and distinguish it from religiosity. ${ }^{5}$ The authors' definition of spirituality is congruent with this definition and is conceived of as relating to the essence of being, the core nature, the energetic gestalt of a person, creature, or thing. Aldwin et al also distinguish between religiousness with its affiliation and service attendance, and spirituality with its meditative and self-transcendent aspects and note their effects on health. ${ }^{6}$ Spirituality can give higher and deeper meaning to a person's life and inspires a person to transcend the ordinary. Spirituality is hidden, not overt, yet can manifest energetically. Spirituality can be experienced from early childhood onwards, with growth in spiritual maturity often following life crises. ${ }^{6}$ High-quality spiritual experiences tend to promote benefit to many rather than to just one person, orientation toward service rather than to fame and fortune, support of love and empowerment rather than fear and negativity, allowing for choice rather than demanding obedience, awareness of a higher power rather than claiming ultimate authority, creativeness rather than rehashing old platitudes, focus and intelligence rather than being effusive and contradictory, and emphasizing the personal effort and labor needed for personal growth rather than claiming that enlightenment can occur without work and effort. ${ }^{7}$ The authors have observed that the spiritual experience is accompanied by a shift in consciousness to a more transcendent realm with broader overall awareness and comprehension of meanings that expands beyond the immediacy of everyday life toward higher and deeper experiences. This is a shift to a higher or deeper self or higher plane or awareness of a higher being or greater source of being that is most likely to be experienced in a spontaneous or an induced trance state, or at least a transpersonal transcendence to heightened and broadened awareness. The transcendence beyond ordinary limits may be accompanied by a sense of nobleness, self-actualization, altruism, or communication with spirits or deities, or merging with a supreme being or with nature. The authors have personally experienced and have had patients and congregants report that this can result in stress reduction and a feeling of wellbeing and a personal sense of inner healing and peacefulness. It can also increase resiliency. Spirituality can be expressed through various religious traditions, but is not confined to religious practice or belief.

On the other hand, spiritual struggle has appeared to predict poor health outcomes consistently. In the example of preparing for cardiac surgery, it has been demonstrated that increased levels of the proinflammatory cytokine interleukin-6 occurred in patients who were struggling spiritually. ${ }^{8}$ This elevation in interleukin-6 associated with negative emotions has been correlated with adverse health outcomes. ${ }^{8}$

The art of spiritual healing in general and of skin specifically involves rising beyond the polarities and dualities of conscious life toward the wholeness of unity ${ }^{9}$ found in a heightened and broadened awareness, often with a shift into an ASC that becomes dimensionless and timeless. Accompanying that spiritual shift and ASC is usually an emotional shift in polyvagal autonomic state ${ }^{10}$ from sympathetic to parasympathetic with an accompanying shift in body chemistry from sympathetic fight or flight to dorsal vagal complex rest, digest, repair and heal, and ventral vagal emotional feeling and expression with transpersonal engagement. The shifts in emotional and autonomic states are often required to facilitate and unblock spiritual and physical healing of the skin.

\section{Brain aspects of spirituality and spiritual healing mechanisms}

Spiritual experiences most frequently occur accompanied by a shift toward or into an ASC. The brain as an operating system has several functional modes. The four major functional modes are the ordinary state of consciousness, which at times includes the hypervigilant state of consciousness, the ASC, the dreamlike rapid eye movement form of sleep, and deep sleep. Healing in general and of the skin specifically is impaired during the hypervigilant state of consciousness and to a lesser extent during the ordinary state of consciousness, while healing is usually allowed to proceed during ASC, rapid eye movement sleep, and deep sleep. ${ }^{10}$ 
The ASC is a daydream-like or trance-like functional brain mode common in childhood but less so in adulthood, often with little if any sense of self-awareness. The individual may be in one of several possible altered states of consciousness, which should be kept in mind whenever there is reference to the ASC. Trance is a deep state of absorption. There is a shift to parasympathetic autonomic nervous system dominance associated with vegetative body activities, such as rest and healing, including healing of the skin. ${ }^{10}$ This is the mode in which spiritual experiences are most likely to occur. The ASC occurs spontaneously and intermittently throughout the waking time. Individuals vary in how easily they can shift into ASC. Some individuals have more innate ability to shift into ASC than others, based on genetic determinants and brain chemistry. One factor is polymorphism of the catecholO-methyltransferase enzyme in the brain that degrades the neurotransmitter dopamine. ${ }^{11,12}$ About $15 \%$ of individuals are high-hypnotizable, shifting readily into ASC, and about $15 \%$ of individuals are low-hypnotizable, shifting into ASC with difficulty, if at all. Most individuals (about 70\%), are intermediate in their ability to shift into ASC. ${ }^{13}$ In deep phases of ASC, the sense of time disappears as does the sense of a separate self. In its place, a person may experience merging into unity (feeling connected with all as one). About $4 \%$ of the population are fantasy-prone, high-hypnotizable, ${ }^{14,15}$ and those individuals are most likely to have more frequent spiritual experiences spontaneously or after training in shifting into higher self during ASC. Others who are dissociative high-hypnotizable or who are medium-hypnotizable may also have spiritual experiences spontaneously or after training in shifting into higher self during ASC. There is a precept that ethical and psychospiritual preparation is important for the individual to become an appropriate vessel to contain the spiritual experience. For the spiritual experience, like many other aspects of life, chance favors the prepared mind.

\section{Spiritual development through time and its relationship to healing skin disorders}

The earliest spiritual-religious practitioners were shamans. Among other activities, shamans practiced healing of spirit, mind, emotions, and body - including skin disorders. Shamanic techniques still have relevance today to promote healing of some skin disorders resistant to conventional approaches. Many shamans in diverse cultures shift into ASC intentionally, often using auditory driving of drumming at a range of $180-420$ beats per minute, most commonly at 205-220 beats per minute but varying from one culture and individual to another. ${ }^{16}$ At this beat of about 3.5 cycles per second with a first overtone of about 7 cycles per second, brain wave entrainment in the theta range can occur, enhancing shift into the ASC. Alternatively, shamanic auditory driving may be done using clicking sticks or rattles. ${ }^{16}$ Repetitive chanting and singing may also induce ASC in shamans and other participants in the ceremony. In some cultures, hallucinogenic or otherwise mind-altering plant materials may be used to assist the shaman in attaining ASC. Dancing and fasting are other methods for attaining ASC. The shaman enters the ASC with special training and experience for specific purposes, and in a specific cultural setting with expectations for specific content. This mode is termed by the authors as the shamanic state of consciousness and content (SSCC), and corresponds with what Rock and Krippner call shamanic patterns of phenomenal properties. ${ }^{17}$ Again, the individual may be in one of several possible altered shamanic states of consciousness, which should be kept in mind whenever there is reference to the SSCC. The shamanic state of consciousness and the content are two separate aspects that are combined in the SSCC. Required contents for the SSCC include a visual mental image or its equivalent in another sensory system such as auditory or kinesthetic, the outward appearance of that image must be consistent with a shamanic cosmology, the image must be consistent with the purpose of the shamanic journey, and the function of the vision must be consistent with the vision. ${ }^{17}$ For the shaman, the nonphysical world encountered in the SSCC may be considered equally as real as the physical world. ${ }^{17}$ Shamans were among the first psychotherapists, physicians, magicians, performing artists, storytellers, and weather forecasters. ${ }^{17}$ Some could also locate game animals, enemy positions, or lost objects. Typical shamanic spiritual treatment elements include suggestion and imagery, discovery of the cause, removal or release of the cause, followed by subconscious relearning. These treatments can be directed when needed toward healing skin conditions, as discussed further below.

In traditional Eastern culture, the ASC may also be intentionally entered through concentrative meditation or mindfulness meditation and in traditional Western culture more commonly through hypnosis, ${ }^{2}$ but without the specific shamanic content. Hassidic Jews commonly use ASC during mystical chanting, dancing, prayer, and other rituals. ${ }^{18}$ Their leader, the Rebbe or a Tzadik, employs shamanistic methods for soul retrieval, fiery transformations, purification, telepathic communication, prophesy, and magical healing. ${ }^{18}$ The Hebrew unpronounced word יהוה consisting only of vowel sounds and traditionally vocalized as Adonay (Lord) 
or HaShem (The Name) according to Jewish Midrash is a simultaneous combination of the verbs "was, is, will be" and imparts a sense of energy rather than of a "thing". ${ }^{19}$ This energy could be used for healing. Written language also, through its abstract symbolic nature, tends to shift toward male social dominance and linear active left brain processes, while images in their concrete symbolic nature tend to shift toward female social dominance and nonlinear healing right brain processes. ${ }^{20}$ Intentional shifting from one hemisphere to the other may be achieved by closing the contralateral nostril with finger pressure and breathing through only one nostril. ${ }^{21}$ This method has been practiced for centuries in yoga and can help shift the individual toward relaxation and healing of the skin. ${ }^{10}$

The ASC usually affords access to the subconscious and to the superconscious. Quieting the ordinary state of consciousness and shifting to ASC permits listening to the subconscious, which is otherwise usually drowned out by the chatter of the ordinary conscious state. Being in the ASC also allows intentional changes in autonomic regulation, immune regulation, and other aspects that are not under the usual conscious control of the ordinary state of consciousness. Shifting to ASC also allows listening to or experiencing the superconscious, the "higher self". The right temporal lobe of the brain has been implicated in spiritual experiences that may occur in ASC or associated with right temporal lobe epilepsy. ${ }^{22}$

Spiritual experiences generally occur in ASC, whether spontaneous or induced by drumming, chanting, or other inducers of the ecstatic or trance state, and often involve the superconscious or "higher self". The ASC corresponds to what we know as nonordinary reality. It is associated in an indigenous Mesoamerican terminology with the nagual (pronounced na-wal) totem of the nonmaterial world of energy and spirit, ${ }^{23}$ perceived with nonordinary awareness and in kabbalistic terminology with עולם הנסתר Olam Ha Nistar or "the concealed or hidden world". Other terms for nonordinary reality in other cultures include the unconscious mind, transpersonal fields, the life force, the collective unconscious, the chakras, the Tao, and the spirit world. ${ }^{24}$ The content of the spiritual experience is influenced by culture, training, beliefs, expectations, and motivations and yearnings. Because spiritual experiences are in ASC and nonordinary reality, the spiritual experiences often become difficult to express or to remember accurately in the ordinary state of consciousness and ordinary reality. Some shamans and mystics develop the ability to transition rapidly back and forth between nonordinary reality and ordinary reality by shifting between trance and ordinary alert states. Other shamans and mystics develop the ability to remain in a very light trance or SSCC for prolonged periods where they can perceive nonordinary reality and ordinary reality simultaneously. Trance induction was indicated on a 3,000year-old stele in Egypt, in sleep temples in ancient Greece, and in the Bible at Genesis 2:21, 1 Samuel 26:12, Job 4:13 and $33: 15$, and Acts $10: 10 .{ }^{25}$ Healing insights or instructions may occur during ASC in nonordinary reality that assist in helping to improve skin problems.

Spiritual experiences may also occur during dreaming in rapid eye movement sleep. Again there may be difficulty remembering the spiritual experiences accurately upon awakening, so some use journaling at intervals during the night or immediately upon awakening to preserve the dream contents. Some shamans, such as those in Australia, use the dream time more than ASC as their preferred mode of spiritual connection. Spiritual dream experiences are recorded repeatedly in the Bible $^{26}$ in Genesis 20:3, 20:6, 31:10, 31:11, $31: 24,37: 5,37: 6,37: 9,37: 10,40: 5,40: 8,40: 9$, 40:16, 41:7, $41: 8,41: 11,41: 12,41: 15,41: 17,41: 22,41: 25,41: 26$, and 41:32, Numbers 12:6, Judges 7:13 and 7:15, 1 Kings $3: 5$, Job 20:8 and 33:15, Psalms 73:20 and 126:1, Ecclesiastes 5:3, Isaiah 29:7, Jeremiah 23:28, Daniel 2:1, 2:3, 2:4, 2:5, 2:6, $2: 7,2 ; 9,2: 26,2: 28,2: 36,2: 45,4: 5,4: 6,4: 7,4: 8,4: 9,4: 18$, 4:19, and 7:1, Joel 2:28, Matthew 1:20, 2:12, 2:19,2:22, and 27:19, and Acts 2:17. Dream interpretation is complex and can become quite esoteric, such as the Zoharic kabbalistic explication of Joseph's interpretation of Pharaoh's dream described in Wolfson's book on dream interpretation. ${ }^{27}$ Dreams may also provide insights or instructions in how to help heal skin disorders.

\section{Religion and religious healing as it relates to skin}

Religion also has many definitions. The anthropologist Clifford Geertz defined religion as a "system of symbols which acts to establish powerful, pervasive, and long-lasting moods and motivations in men by formulating conceptions of a general order of existence and clothing these conceptions with such an aura of factuality that the moods and motivations seem uniquely realistic" ${ }^{28}$ Religion, as described by the authors for the purposes of this paper, is congruent with this broad definition and is a personal or group attempt to make sense of the world and to learn how to behave based on beliefs, practices, and cultural, linguistic, and many other factors.

Organized religion is a group of believers who accept a common set of beliefs, practices, and rituals derived from 
sacred stories and myths. There is broad acceptance based on moments of heightened consciousness or ASC of historical and mythological figures regarding spiritual issues that concern existence and meaning. Religion has also been facetiously defined as being the politics of spirituality (attributed to Bill Olson). Often a religion is based on the spiritual experiences of the mythical or real leader or leaders who formed the religion. A person can have spiritual experiences and not be religious, or a person can be religious but unaware of or uninterested in spiritual experiences. In kabbalistic terms, spirituality can be associated with the loving kindness of the sephira of Chesed, being open and spontaneous, freeing, warm, fruitful, and full of light, while religion can be associated with the strength, discipline, boundaries, and restrictiveness of the sephira of Gevurah, being ritualistic, legalistic, limiting, and sometimes concerned with domination..$^{29}$ Religion without the spirit is often lifeless, but spirituality without religion may be too lacking in discipline. Kabbalistic healing rituals have been developed, including rituals for healing skin disorders, such as visualizing the sefirotic flow of energy for healing skin disorders.

With respect to religious historical development and religious healing, shamans preceded other forms of religious practitioners. Considerable insight into religious development can be obtained through familiarity with shamanism. Garb presents the Hassidic Tzadik as a shamanistic practitioner. ${ }^{18}$ An analysis of magicoreligious practitioners by Winkelman ${ }^{30}$ showed that there are four main groups of practitioners worldwide, ie, shaman, priest, diviner, and sorcerer/witch. The shaman is generally found in hunter-gatherer societies without agriculture and uses SSCC for healing and divination. The word "shaman" derives from the Russian adaptation of the Tungus "saman", meaning "one who sees". Each shaman usually has several helping spirits the shaman encounters and with whom the shaman develops relationships with when in SSCC. Tales of shamans journeying or witches flying reflect their use of ASC. ${ }^{31}$ With adoption of agriculture and a semisedentary lifestyle, the role of the shaman is adapted to that of a shamanic healer with continued use of SSCC to a lesser extent, to a shamanistic healer with less use of SSCC, to a medium with continued use of ASC, or to a healer without much if any use of ASC. The priest employs sociopolitical and religious power over believers and engages in magicoreligious agricultural rites and propitiation of gods for socioeconomic protection, largely through sacrifices of one type or another. Priests generally do not use ASC and may not have had direct experiences with spirits. Krippner and Welch used Winkelman's categories in describing a number of contemporary shamans, shamanic healers, shamanistic healers, priests and religious healers, mediums and spiritists, and sorcerers and witches, many of whom they interviewed. ${ }^{7}$ Each of these can be involved in religious healing, some more than others. The placebo effect is one factor in achieving a healing. The typical healing sequence within the specific framework of the particular cultural and religious beliefs is first disruption of habitual frames of reference, then reframing the situation as a transformative process in pursuit of revitalization and healing. ${ }^{18}$ This applies to healing of skin disorders as well.

\section{Spiritual aspects of skin}

Physical attributes of one's own skin contribute to the spiritual core concept of self and others. The skin is the largest organ of the body and provides separation and protection, touch and contact, expression and representation, maternalinfant bonding with breast feeding stimulating release of oxytocin in the brain, intimate sexual contact and frictional stimulation with release of oxytocin in the brain at climax, excretion through sweat, and temperature regulation through dilation or constriction of surface blood vessels and through evaporation from sweating. Emotional sweating changes are easily detected by electrodes through galvanic skin resistance measurements, and measurement of the galvanic skin response is an important part of "lie detector" tests. ${ }^{32}$ The skin is both the separator and the connector between self and others, and can affect spiritual intimacy with another, a spiritual leader, or a higher power. The skin projects to self and others both physical health or illness and emotional reactions and responses. Skin, hair, and nails at times may reflect inner issues of the body, emotions, psychological states, and spiritual being and meaning. ${ }^{9}$

The nervous system and the skin remain intimately connected throughout life. The more spiritually developed the person becomes, the more aware he or she is of what drives his or her life choices, and whether the ego or the soul is directing. On the physical sensation level, this occurs as molecular, biochemical, and electrical interactions between skin cells and nerve cells. On the emotional feeling level, skin blushing or pallor and warmth or coldness reflect some emotional states. On the cognitive thought level, the appearance of our skin, hair, and nails influences our thoughts and vice versa. Anzieu ${ }^{33}$ speaks of the skin ego, a psychological semipermeable membrane that separates self from other but permits interchange. On the social level, the appearance of our skin, hair, and nails influences social interactions as well as internal psychical self interactions. ${ }^{34-36}$ On the spiritual level, the perception of the skin can influence the core self, 
relationships between people, and a person's relationship with the Great Unknowable (also known spiritually and religiously as God, יהוה [YHVH, voiced as Adonay], Allah, Manitou, Wakan Tanka, and a multitude of other names).

There are numerous metaphors relating to skin. Sensitive people may be referred to as "thin-skinned", while insensitive people are called "thick-skinned". Irritation may be expressed as "he got under my skin". These boundary metaphors sometimes include spiritual overtones. ${ }^{37}$ For example, the metaphor of shedding one's skin like a snake can invoke an image of inner growth and transformation. All of these aspects and thoughts related to skin add to the spiritual core concept of self and others.

The skin is also associated with subtle energies, electrical charges, auras, energy meridians and points, and other features often less detected and described in Western culture. ${ }^{38}$ These can variously be seen, palpated (felt), or detected by effects produced. Acupuncture meridians have been most elaborately described in traditional Chinese medicine, but have been noted in other cultures also.

The type and extent of clothing can have spiritual as well as social and religious aspects. Clothing covers the skin and can vary from none such as in certain tribal cultures or nudist camps to complete coverage of all skin, such as a burqa. Varying degrees of individual expression are acceptable amongst different cultures. Clothing represents nonverbal communication and social identity. ${ }^{39}$ While tightly woven cloth or animal skin clothing protects the skin from ultraviolet damage and can protect the skin from heat, cold, and some forms of physical trauma, it can also have designs on it based on spiritual visions.

Skin coloring with makeup, paint, or tattooing has reflected spiritual aspects and dimensions. Examples of the spiritual and social value of applying red paint on the skin have been present in many cultures from ancient times to the present day. Red ochre coloring, a natural earth pigment with iron in hematite or dehydrated iron oxide form, for painting skin has been identified from 100,000 years ago at Blombos Cave, South Africa. ${ }^{40}$ Pict warriors in Scotland painted themselves with red ochre as did Chumash Indians in California and the Moche in Peru. Ancient Egyptian women used it as lipstick and rouge. Bones painted with red ochre were found in Australia dating back 62,000 years. Australian aborigines have used red, yellow, and brown ochre for painting their bodies, boomerangs, and rock art based on spiritual visions during dreamtime. Currently, the Maasai paint their bodies with red ochre. This red paint on the skin has been associated with blood, power, fertility, life, and death, all of which have been further associated with spiritual and existential quests. $^{40}$

Makeup can in some instances reflect spiritual selfexpression based on visions. It includes various shades of paint, base, powder, blusher, eye liner, eye shadow, and lipstick. Hair coloring with various dyes and bleaches is also widespread, as is the use of curling and straightening processes. These can also help depict spiritual experiences or visions. Facial masks based on visions have been worn for spiritual as well as religious purposes. ${ }^{41}$ Wigs and hair weaves also change the appearance. Some orthodox Jewish women wear a sheitel as a form of modesty as a spiritual or religious practice. While in Western culture skin coloring with makeup, hair dying, and nail polish are often used primarily to enhance attractiveness and to mask flaws in the skin, hair, or nails; in some cultures they can also indicate social status and individualistic expression, including spiritual aspects. In India, the bindi dot on the forehead is an indication of high caste. Women in India traditionally color their hair part with henna, and for their wedding often have elaborate patterns of henna staining on their hands. Subcultures and religions have their own norms and taboos with respect to skin, hair, and nail coloring. This can have both religious and personal spiritual symbolism. ${ }^{41}$

Skin tattooing can be performed by piercing the skin with a needle covered with pigment. Charcoal has served as a black tattoo pigment for centuries. Perhaps the first tattoos were accidental, with the skin being pierced by a sharp burned stick coated with charcoal soot. ${ }^{42}$ Ötzi, a 5,300-year-old mummy found frozen in the Ötztal Alps, had 39 tattoos, many located at acupuncture sites, and correlated with evidence of disease, such as arthritis, for which use of those acupuncture sites could have been beneficial. Other prehistoric frozen mummies from Siberia, Peru, and Chile have been discovered with decorative tattoos. ${ }^{42}$ The word tattoo comes from the Tahitian word "tatu" that means to mark something. In Tahitian mythology, one of the sons of the creator taught humans the art of tattooing. This was considered a sacred art form or "tapu" and was performed by shamans "tahua" who knew the religious ritual associated with tattooing, the meaning of the designs, and the methodology. ${ }^{43}$

Skin piercing allows attachment of ornaments to the skin. While the most common is pierced earlobes, pierced umbilicus, eyebrow, nostril, lip, tongue, nipple, or genitals are also found. They can be a form of spiritual expression through the symbolism of the ornament as well as having other individual, social, and cultural dimensions.

Intentional scarring of the skin can be an expression of spirituality or culture. Some individuals form hypertrophic 
scars, and in groups where this trait is common, patterns of scarring can help to identify individuals as well as permit individual spiritual expression based on visions.

Scalp hair can be grown long, cut short, shaved, dyed, bleached, made wavy or straight, and worn in many styles. Within a given range of cultural acceptance, there is often a fairly wide range of opportunity for individual expression with scalp hair, and in men with beard hair. This permits individual spiritual expression based on visions or others' spiritual experiences. Body hair can also permit spiritual expression within a culturally acceptable range.

\section{Religious aspects of skin}

Skin and skin disorders have also had religious aspects since ancient times. How much skin is covered with what kind of clothing, how the scalp and beard hair are cut and styled, skin, hair and nail coloring and decorating, skin tattooing, skin piercing with wearing of ornaments, and intentional scarring of skin all have had and continue to have spiritual and religious significance. Skin, hair, and nails are visible to self and others, and are touchable by self and others. At the outer layer of the body that presents itself to self and others, skin has major psychological and social effects on how we view self and others. Persons with visible skin disorders have often been stigmatized or even treated as outcasts. Various skin disorders, such as psoriasis, leprosy, and vitiligo, have spiritual and religious aspects. Religious aspects of skin and skin diseases are evaluated for several major religions, with a special focus on Judaism, both conventional and kabbalistic.

Religious beliefs and customs often determine the cultural norms of believers with respect to how much skin is exposed, types of clothing worn, type if any of skin painting or cosmetics, use of facial masks and costumes in ceremonies, hair styles and coloring, nail styles and coloring, tattooing with religious themes, scarification, piercings, and types of jewelry worn that have religious significance. The anthropological literature ${ }^{43}$ has extensively described these factors for many cultures and the religious meanings attached to them in each culture and religion.

The skin is mentioned in the Hebrew Bible a number of times, and reflects specific religious values and goals. For example, when Moses descended from Mount Sinai, the skin ohr עור of his face shone karan קרן like rays of light ${ }^{26}$ (Exodus 34:29, 34:30, 34:35). The Hebrew word עור for skin is pronounced the same as the Hebrew word אור for light, further suggesting some connectedness between skin and light. Light is a prominent metaphor for spiritual flow of beneficent energy.
Returning a borrowed cloak by sunset to permit the owner to cover the skin with it for night-time sleep is mentioned in Exodus 22:27. In Judaism, as in other religions, moral behavior is foundational for personal development. Ezekiel's vision of redemption consisted of reconstituting the body from dried bones including the covering of the body with skin (with these resurrected people symbolizing the hope for a return of the people from exile to the land of Israel) (Ezekiel 37:6, 37:8, 37:12). Micah described the skin being flayed off ("skinned") in Micah 3:3. If a slave agreed to be a permanent slave, the antithesis of the laws governing slavery, his ear was pierced with an awl as described in Exodus 21:6 and Deuteronomy 15:17. Otherwise, piercing and tattooing is proscribed in orthodox Jewish practice. ${ }^{44}$

Male circumcision involves cutting off the penile foreskin, as was done starting with Abraham in Genesis 17:10, 17:12, $17: 13,17: 14,17: 23,17: 24,17: 25,17: 26$, and 17:27, and continues to be practiced by Jewish families to this day. This removal of a portion of the male genital skin empowers a male child to be entered into a sacred covenant within Jewish tradition. This has both religious significance and health effects. Skin infections that tend to occur under the foreskin are usually avoided in the circumcised. Abraham circumcised Isaac at 8 days of age in Genesis 21:4. Circumcision of the penile foreskin is prescribed in Genesis 34:1, 34:22 and in Exodus 12:44, 12:48, Leviticus 12:3, and Joshua 5:3, 5:5, 5:7. Jewish males continue to be ritually circumcised when 8 days of age and are thereby entered into the covenant of Abraham. By analogy, circumcising the foreskin of your heart is spoken of in Deuteronomy 10:16, Deuteronomy 30:6, and Jeremiah 4:4 as ways of spiritually and religiously overcoming the hardened heart. Skin color is mentioned in Jeremiah 13:23: "Can the Ethiopian change his skin, or the leopard his spots?" Boils were mentioned as one of the ten plagues in Exodus 9:11 and as afflicting Job from head to toe in Job 2:7. Lice were also mentioned as one of the ten plagues in Exodus 8:16-18 that preceded the liberation by יהוה (this holy name is not translated in Jewish tradition, it is too holy to be spoken) of the Israelites from Egypt. Ritual cleansing of a priest or other person was performed by placing blood from a ritually sacrificed animal onto the skin of the right ear, right thumb, and right great toe in Leviticus 14:14, 14:17, 14:25, or oil could be used in place of blood as in Leviticus 14:28. Blood was considered to contain the spiritual life force of the animal. Anointing the skin on a person's head with oil was also considered a sanctifying act when performed in the appropriate ritual, as in Exodus 28:41, 29:7, 30:30, 40:15, and Leviticus 16:32. Anointing the skin of a king sanctified him, as in Judges 9:8, 1 Samuel 9:16, 15:1, 
16:22, 1 Kings 1:34, 19:15, 19:16. Anointing the skin with oil continues to be a way of consecrating (making sacred) Christian priests, ministers, and lay people. Washing the skin with water in a ritual bath was also a common form of spiritual cleansing, as in Leviticus 15:5, 15:6, 15:7, 15:8, 15:10, 15:11, 15:13.15:18, 15:21, 15:22, 15:27, Leviticus 16:26, 16:28, Leviticus 17:15, 17:16, Numbers 19:7, 19:8, 19:19. ${ }^{26,45-47}$ Immersing three times in a ritual bath called a "mikvah" has continued to be a Jewish spiritual practice, performed after menses, before marriage, after childbirth, at conversion, before Shabbat and other holidays, and at other appropriate times or times of need of spiritual cleansing or transformation. Similarly, baptism was used by John the Baptist, as in Matthew 3:11, Mark 1:4, 1:8, Luke 3:16, John 1:26, 1:33, to cleanse his followers and to cleanse Jesus. Cleansing the skin with water by immersion or sprinkling has continued as baptism in Christianity and in the Mandaean faith. Symbolically, it is not just the skin but the whole person that is cleansed and sanctified in most of these religious traditions.

Religious clothing can be considered a second skin. It varies from none for certain Hindu holy men $^{48}$ to mostly covered, as with traditional Roman Catholic nuns, other Christian monks, nuns, and priests, ${ }^{39}$ Muslim women wearing the hijab with or without veil, Buddhist monks and nuns in flowing robes with shaven scalps, shamans in costumes with or without masks, Jewish men with kippot head coverings, prayer shawls, and tefillin, and a wide variety of other types of clothing with religious significance. Amulets may be worn as necklaces for protection.

Tattoos were banned in Judaism based on the injunction in Leviticus 19:28 not to tattoo, perhaps in part because surrounding peoples that the Jews separated from did tattoo. Tattoos and piercings are prohibited in traditional Judaism because the dead are expected to rise from their graves with the arrival of the Messiah. The bodies are expected to look the same as before death and be in their original created states. Tattoos were also discouraged in Christianity based on considering the body a temple of the Holy Spirit in 1 Corinthians 6:19-20. ${ }^{43}$ In Hinduism, tattoos were widespread and represented devotional themes. A number of cultures, including the Maori in New Zealand and the Lakota in North America, believed that after death a spirit would recognize the tattoo patterns specific to the tribes and allow them passage into the afterlife. ${ }^{43}$ Many cultures also used tattoos for protection to ward off misfortune or evil. Ainu women in Japan tattooed their body with an image of their goddess for protection. ${ }^{43}$ Islamic Iraqis may tattoo a dot on the tip of a child's nose for protection against illness. In Southeast
Asia, Buddhists in Myanmar, Cambodia, and Thailand often believe in the protective power of a tattoo. Sacred texts and images may cover large portions of the body. ${ }^{49}$ In Thailand, an initiation rite called the "Krob Kru" involves a religious ritual with tattooing sacred text followed by testing of the protection with sword swipes performed by a shaman. ${ }^{50}$

\section{Spiritual aspects of skin disorders}

The skin is a great projection screen onto which physical, emotional, mental, and spiritual aspects of the person are constantly made visible. ${ }^{9}$ As with other challenging physical conditions, visible skin disorders can have significant psychological and social effects. The afflicted person may seek to understand if there are spiritual implications buried beneath the skin disorder, either as a matter of being deserved or of reflecting their psychic shadow. According to Dethlefsen and Dahlke, ${ }^{9}$ the polarity resulting from the person not unifying with their shadow aspects can result in psychological disturbances, functional psychosomatic disturbances, acute physical disturbances such as acute skin inflammation, chronic conditions such as acne or psoriasis, incurable processes such as metastatic melanoma, or karmic conditions such as congenital defects or genetic abnormalities.

Inflammatory skin disorders such as acne and skin eruptions may point to a variety of spiritual concerns. Childhood atopic dermatitis or eczema can impair child-maternal relationships, and early childhood relationships are often key factors in a person's capacity to experience spiritual and psychological intimacy. Itching can sometimes mean that something is biting or "bugging" a person on a psychospiritual level. Psoriasis can symbolically provide an armored shell for protection, but it can also impair emotional and spiritual intimacy. Congenital skin defects such as hemangiomas or large nevocellular nevi can impair the appearance, as can genetic skin disorders such as ichthyosis ("fish-skin disease"). Visible benign tumors such as syringomas or seborrheic keratoses can impair appearance. Malignant tumors such as basal cell or squamous cell carcinoma can lead to treatments that result in disfigurement from scarring. Malignant melanoma, if invasive, can become metastatic and life-threatening. All of these physically deforming conditions can raise existential issues and provoke searches for meaning in the afflicted.

Flaherty $^{51}$ sought relief from his severe eczema through shamanic rituals in Peru that involved shamanic counseling and chemically ASC through ayahuasca. His eczema had failed conventional medical treatments and acupuncture in England, and he had been incapacitated for a year. After a number of shamanic rituals involving ayahuasca in the 
Peruvian Amazon, he felt a dramatic spiritual shift and his eczema cleared rapidly; he has remained almost clear for over 7 years following the spiritual experience. Sandra Ingerman, a well known shamanic practitioner, has stated to one of the authors (PDS) that she has seen some good results with rashes and eczema being healed from shamanic work, but she has not written down or published these experiences.

Carson $^{52}$ reported that a primary care physician colleague of hers had a female patient with a cutaneous ulcer from a non-healing spider bite reaction and also had depression. The ulcer had failed to heal despite 17 previous surgeries. While the patient was hospitalized, the physician with the patient's permission did a shamanic journey for her, employing the physician's helping spirits. When the physician later discussed the shamanic journey with the patient, her depression lifted and she was able to have two successful skin grafts for the first time over the ulcer at the bite area.

LeShan $^{53}$ described a case of distance healing of psoriasis through prayer. A man with intractable psoriasis for 18 months noted a change when a healer 50 miles away prayed to God to do whatever was best for the healee. The psoriasis improved and disappeared within a few days, staying clear on follow-up 2 years later.

Psychosomatic hypnoanalysis can also be used to explore the psychological and spiritual aspects of skin disorders. Using the mnemonic "COMPASS" for the seven key issues described by LeCron and Cheek, ie, conflict, organ language, motivation, past traumatic experiences, active identification, self punishment, and suggestion, it is possible in hypnotic ASC to explore these areas for psychological and spiritual issues that relate to the skin disorder. ${ }^{54}$ Conflict is usually between "I want" to do one thing and "I ought" to do another, and can result in itching, hives, rashes, or other skin issues. The organ language involves the skin, for example, "he got under my skin", "she made my skin crawl", and "I have been itching to". Motivation or secondary gain often involves being excused from having to do certain duties or obligations because of the skin disorder.

Past traumatic experiences involve a memory that links to the skin. For example, Ewin and Eimer ${ }^{55}$ relate use of psychosomatic hypnoanalysis with a medical student who got hives every time that he ate chocolate. When the medical student was age-regressed in trance to about 4 years of age, he recalled visiting a zoo with his parents on a Saturday afternoon. It happened to be feeding time for the snakes, and he witnessed with great horror as a large snake ingested a rabbit. The next morning happened to be Easter Sunday, and of course he found in his Easter basket a chocolate bunny. Upon eating the chocolate bunny, he broke out in hives, and continued to get hives every time he ate chocolate thereafter. Ewin provided suggestions that he would no longer need to develop hives when eating chocolate. The medical student was able to process this recovered memory as an adult and tested himself by eating chocolate and no longer developed hives.

Active identification occurs when a powerful other, such as a parent, had a similar skin problem. Self punishment occurs when the skin disorder is related to something that the person feels guilt about. Suggestion occurs when a powerful other, such as a parent, suggests something related to the skin that the person internalizes subconsciously. Sometimes these items may have spiritual aspects of existential concerns or meanings that require some exploration or reframing. Another example related by Ewin and Eimer was of a Roman Catholic priest who developed intense skin itching shortly after a married woman parishioner made a pass at him. Ewin told the priest that it was obvious what the priest was itching for, and then quoted biblical passages and reframed the incident, after which the priest's itching promptly went away. ${ }^{55}$

\section{Religious aspects of skin disorders}

Skin diseases rather vaguely specified, and often translated as a rising, a scab, a bright spot, a white spot like the plague of leprosy tsara'at צרעת, are mentioned in the Hebrew Bible in a number of locations. The word "tsara'at" means to be thrown down or humiliated. The King James version of the Bible translates tsara'at as leprosy, but this is not how the word is translated by Hebrew biblical scholars, such as Milgrom. ${ }^{56}$ In biblical times, this condition was more likely akin to psoriasis or vitiligo than to our modern understanding of the mycobacterial disease leprosy. ${ }^{56}$ Scaling disease that penetrates into the skin, often translated as leprosy, was seen as a physical punishment for religious or moral transgressions. In Exodus 4:6-4:8, Adonay instructed Moses to put his hand inside his cloak and when Moses took it out, it was leprous like snow. Moses was told to put his hand back in his cloak and it came out normal. Moses was to use this as a sign of God's power to punish. Leprosy was discussed extensively in Parsha Metzorah (meaning "leprous"), Leviticus 13:2, 13:3, 13:4, 13:5, 13:6, 13:7, 13:8 (shiny marks deeper than superficial); 13:9, 13:10, 13:11, 13:12, 13:13, 13:15 (discolorations); 13:18, 13:20, 13:21, 13:22 (boils); 13:24, 13:25, 13:26, 13:27, 13:28 (burns); 13:29, 13:30, 13:31, 13:32, 13:34, 13:35, 13:36 (sores); 13:38, 13:39 (white spots); 13:42, 13:43, 13:44 (discolored baldness); 13:45 (requirement to cry "unclean" and live apart); 13:47, 13:48, 13:49, 13:51, $13: 52,13: 53,13: 56,13: 57,13: 58,13: 59$ (spots on fabrics), and Leviticus 14:2, 14:3, 14:7, 14:32 (cleansing of cured leper); 14:34, 14:44, 14:54, 14:55, 14:57 (spotted mildew on houses 
also considered to be leprosy); also Deuteronomy 24:8, 2 Kings 5:1, 5:3, 5:6, 5:7, 5:27, and 2 Chronicles 26:19. Persons with these conditions were considered ritually impure, with the presumption that their skin disorder was associated with transgression or immorality. The person was to be separated from the community for 7 days and then re-examined by a priest. They were to cry out "unclean" when others approached so that the others could avoid spiritual, but interestingly not physical, contamination. The ancient Jews believed that certain transgressions were airborne, and it was exposure to the spirit of the transgressor, above its manifestation through the skin that needed to be avoided though quarantine of the individual affected. However, once the penitent's skin had cleared, he or she was cleansed through a priestly ritual and welcomed back into the community. Levites who had skin blemishes or skin disorders were not permitted to function as priests. When Miriam slandered Moses in Numbers 12:1-15, Adonay summoned Moses, Aaron, and Miriam to the Tent of Meeting and afflicted Miriam with leprosy like snow in Numbers 12:10. Nachman $^{57}$ attributed leprosy to slander based on the story of Miriam. Moses prayed for Adonay to heal her. Miriam was quarantined for a week and was healed, and rejoined the community. Midrash Tanchuma Metzora 7, 24a, and 22b extends the notion that leprosy is a punishment for slander. ${ }^{58}$ The biblical concept of leprosy and being ritually unclean was extended to spotted clothing and spotted houses.

In the New Testament, leprosy (lepra $\lambda \dot{\varepsilon} \pi \rho \alpha$ ) is mentioned in Matthew 8:3, Mark 1:42, Luke 5:12, 5:13. Christians associated leprosy with sin. Leprosy (البرص) is also one of the diseases mentioned in the Quran in the context of the miracles of the prophet Jesus, in verse 5:110 of chapter 5 sūrat 1-māidah (The Table Spread with Food). The Greek "lepra" means scaly or defilement. Many scaly skin disorders occur that in ancient times were not differentiated from leprosy, including psoriasis, dermatitis, xerosis, ichthyosis, and the mycobacterial disease currently known as leprosy. Similarly in Hinduism in ancient India, the Atharava Veda (about 2000 BC) and the Laws of Manu (1500 BC) mention various skin diseases translated as leprosy. The Laws prohibited contact with those affected by leprosy and punished those who married into their families, ostracizing those with the disease for their past sins. The Sushruta Samhita (600 BC) recommended treating leprosy (or kushtha, meaning "eating away" in Sanskrit) with oil derived from the chaulmoogra tree. While Hinduism usually considered suicide a sin, for leprosy it was not. ${ }^{59}$ In Buddhism, leprosy was considered karma and the person was an outcast, but considered compassionately with assistance in local leprosaria. Mycobacterium leprae as the causative organism was not identified until 1873. Other skin diseases such as psoriasis and vitiligo may be mistaken by lay persons for leprosy. Social aversion to skin disorders has promoted ostracism of individuals with those skin disorders that still plays a role in current society and is often supported by religious beliefs, although compassion can be a modifying factor. ${ }^{59}$

\section{Conclusion}

This review has just started to scratch the surface of the spiritual and religious aspects of skin and skin disorders. What and how much skin is exposed, how the skin is painted or decorated, tattooed, scarified, pierced, hair styled, nail styled, and accessorized is determined by cultural norms, personal preferences, spiritual aspects, and religious beliefs and norms. Reactions to skin disorders have had and continue to have extensive spiritual and religious aspects. Those afflicted with skin disorders have often suffered as a result. Examples have been included of spiritual and religious healing of skin disorders by shamans and others through prayer and ritual and by following spiritually obtained instructions, often during ASC or during dreamtime. Modern understandings of skin disorders and how to treat them have brought important advances, but healing of the skin continues to have a spiritual aspect and sometimes even today healing is hindered until the spiritual aspect is adequately addressed.

\section{Acknowledgment}

Debrah Shenefelt is Rabbi of Congregation Or Ahavah, a Jewish Renewal community.

\section{Disclosure}

The authors report no conflicts of interest in this work.

\section{References}

1. Denby K, Duffy N, Tausk F. Psychoneuroimmunology in Dermatology. In: Norman RA, Shenefelt PD, Rupani RN, editors. Integrative Dermatology. New York, NY, USA: Oxford University Press; 2014.

2. Shenefelt PD. Hypnosis, hypnoanalysis, and mindfulness meditation in dermatology. In: Norman RA, Shenefelt PD, Rupani RN, editors. Integrative Dermatology. New York, NY, USA: Oxford University Press; 2014

3. Spiegel D. Mind matters in cancer survival. JAm Med Assoc. 2011;305(5): 502-503.

4. Sheldrake P. A Brief History of Spirituality. Somerset, NJ, USA: WileyBlackwell; 2007.

5. Del Rio CM, White LJ. Separating spirituality from religiosity; a hylomorphic attitudinal perspective. Psycholog Relig Spiritual. 2012;4(2):123-142.

6. Aldwin CM, Park CL, Jeong Y-J, Nath R. Differing pathways between religiousness, spirituality, and health: a self-regulation perspective. Psycholog Relig Spiritual. 2014;6(1):9-21.

7. Krippner S, Welch P. Spiritual Dimensions of Healing. New York, NY, USA: Irvington Publishers; 1992. 
8. Ai AL, Seymour EM, Tice TN, Kronfol Z, Bolling SF. Spiritual struggle related to plasma interleukin-6 prior to cardiac surgery. Psycholog Relig Spiritual. 2009;1(2):112-128.

9. Dethlefsen T, Dahlke R. The Healing Power of Illness: The Meaning of Symptoms and How to Interpret Them. Shaftesbury, UK: Element Books Ltd; 1990.

10. Porges SW. The Polyvagal Theory: Neurophysiological Foundations of Emotions, Attachment, Communication, and Self-regulation. New York, NY, USA: Norton; 2011.

11. Bilder RM, Volavka J, Lachman HM, Grace AA. The catechol-O-methyltransferase polymorphism: relations to the tonic-phase dopamine hypothesis and neuropsychiatric phenotypes. Neuropsychopharmacology. 2004;29(11):1943-1961.

12. Szekely A, Kovaks-Nagy R, Banyai E, et al. Association between hypnotizability and the catechol-O-methyltransferase (COMT) polymorphism. Int J Clin Exp Hypn. 2010;58(3):301-315.

13. Woody EZ, Barnier AJ, McConkey KM. Multiple hypnotizabilities differentiating the building blocks of hypnotic response. Psychol Assess 2005;17(2):200-211.

14. Wilson SC, Barber TX. Vivid fantasy and hallucinatory abilities in the life histories of excellent hypnotic subjects ("somnambules"): preliminary report with female subjects. In: Klinger E, editor. Imagery. Volume 2. Concepts, Results, and Applications. New York, NY, USA Plenum; 1981.

15. Wilson SC, Barber TX. The fantasy-prone personality: implications for understanding imagery, hypnosis, and parapsychological phenomena. In: Sheikh AA, editor. Imagery, Current Theory, Research, and Application. New York, NY, USA: Wiley; 1983.

16. Harner M. Cave and Cosmos: Shamanic Encounters with Another Reality. Berkeley, CA, USA: North Atlantic Books; 2013.

17. Rock AJ, Krippner S. Demystifying Shamans and Their World: An Interdisciplinary Study. Charlottesville, NC, USA: Imprint Academic; 2011.

18. Garb J. Shamanic Trance in Modern Kabbalah. Chicago, IL, USA: University of Chicago Press; 2011.

19. Cooper DA. God is a Verb: Kabbalah and the Practice of Mystical Judaism. New York, NY, USA: Riverhead Books; 1998.

20. Shlain L. The Alphabet Versus the Goddess. New York, NY, USA: Viking Penguin; 1998.

21. Osowiec DA. Ultradian rhythms in self-actualization, anxiety, and stress-related somatic symptoms. University Microfilm 53, 04B: Dissertation Abstracts International; 1992.

22. Devinsky O, Lai G. Spirituality and religion in epilepsy. Epilepsy Behav. 2008;12(4):636-643.

23. Kaplan L. Tonal and Nagual in Coastal Oaxaca. Journal of American Folklore. 1956;69:363-368.

24. Silverberg FR. Indigenous roots of psychotherapy. In: Carson C, editor Spirited Medicine. Baltimore, MD, USA: Otter Bay Books; 2013.

25. Gezundhajt H. An evolution of the historical origins of hypnotism prior to the twentieth century: between spirituality and subconscious. Contemp Hypn. 2007;24(4):178-194.

26. Strong J, Baker WP. Strong's Complete Word Study Concordance: KJV Edition, Expanded Edition. Chattanooga, TN, USA: AMG Publishers; 2004.

27. Wolfson ER. A Dream Interpreted within A Dream. New York, NY, USA: Zone Books; 2011.

28. Geertz C. Religion as a cultural system. In: Geertz $\mathrm{C}$, editor. The Interpretation of Cultures: Selected Essays. London, UK: Fontana Press; 1993.

29. Kaplan A. Sefer Yetzirah: The Book of Creation. Revised Edition. York Beach, ME, USA: Samuel Weiser; 1997.

30. Winkelman M. Shamanism: A Biopsychosocial Paradigm of Consciousness and Healing. 2nd ed. Santa Barbara, CA, USA: Praeger; 2010 .

31. Winkelman MJ. Shamans, Priests and Witches: A Cross-Cultural Study of Magico-Religious Practitioners. Phoenix, AZ, USA: Arizona State University Anthropological Research Papers No 44; 1992.
32. Shenefelt PD. Complementary psychotherapy in dermatology: hypnosis and biofeedback. Clin Dermatol. 2002;20(5):595-601.

33. Anzieu D. The Skin Ego: A Psychoanalytic Approach to the Self. New Haven, CT, USA: Yale University Press; 1989.

34. Ulnik J. Skin in Psychoanalysis. London, UK: Karnac Books; 2007.

35. Cavanagh SL, Failler A, Hurst RAJ, editors. Skin, Culture and Psychoanalysis. New York, NY, USA: Palgrave Macmillan; 2013.

36. Diamond N. Between Skins: The Body in Psychoanalysis-Contemporary Developments. Malden, MA, USA: John Wiley and Sons; 2013.

37. Benthein C. Skin: On the Cultural Border Between Self and the World. New York, NY, USA: Columbia University Press; 2002.

38. Shenefelt PD. Energy medicine in dermatology. In: Norman RA, Shenefelt PD, Rupani RN, editors. Integrative Dermatology. New York, NY, USA: Oxford University Press; 2014

39. Calefato P. The Clothed Body: Dress, Body, Culture. Oxford, UK: Berg; 2004.

40. Henshilwood CS, d'Errico F, van Niekerk KL, et al. A 100,000 year-old ochre-processing workshop at Blombos Cave, South Africa. Science. 2011;334(6053):219-222.

41. Schildkrout E. Inscribing the body. Annu Rev Anthropol. 2004;33: 319-344.

42. Dorfer L, Moser M, Bahr F, et al. A medical report from the stone age? Lancet. 1999;354(9183):1023-1025.

43. Scheinfeld N. Tattoos and religion. Clin Dermatol. 2007;25(4): 362-366.

44. Talmud Bavli Baba Kama 91b, Talmud Bavli Sanhedrin 103b, and Talmud BavliMakkot 21a.

45. Zodhiates S, editor. The Hebrew-Greek Key Study Bible, King James Version, Revised Edition. Chattanooga, TN, SA: AMG Publishers; 1991.

46. Jewish Publication Society. Hebrew-English Tanakh. Philadelphia, PA, USA: The Jewish Publication Society; 1999.

47. Kohlenberger JR III. The Interlinear NIV Hebrew-English Old Testament. Grand Rapids, MI, USA: Zondervan Publishing House; 1987.

48. Carr-Goman P. A Brief History of Nakedness. London, UK: Reaktion Books; 2010.

49. Marie T. Spiritual Skin: Sacred Tattoos: More Than Skin Deep. Costa Mesa, CA, USA: Emerald Bridge; 2011.

50. Krutak L. Spiritual Skin: Magical Tattoos and Scarification. Wisdom, Healing, Shamanic Power, Protection. Aschaffenburg, Germany: Edition Reuss; 2012.

51. Flaherty M. Shedding the Layers: How Ayahuasca Saved More than My Skin. North Charleston, SC, USA: Create Space; 2012.

52. Carson C. Mastery and Mystery: Models for Today's Healthcare. In Carson C, editor. Spirited Medicine. Baltimore, MD, USA: Otter Bay Books; 2013.

53. LeShan L. Explanations of psychic healing. Am Soc Psychical Res Newsletter. 1990:1-3.

54. Shenefelt PD. Ideomotor signaling: from divining spiritual messages to discerning subconscious answers during hypnosis and hypnoanalysis, a historical perspective. Am J Clin Hypn. 2011;53(3):157-167.

55. Ewin DM, Eimer BN. Ideomotor Signals for Rapid Hypnoanalysis: A How-To Manual. Springfield, IL, USA: Charles C Thomas; 2006

56. Milgrom J. Leviticus 1-16: A New Translation with Introduction and Commentary. In: The Anchor Bible. New York, NY, USA: Doubleday; 1991.

57. Nachman R. The Aleph-Bet Book: Rabbi Nachman's Aphorisms on Jewish Living (Sefer ha-Middot). The Book of Attributes. Jerusalem, Israel: Breslov Research Institute; 1986.

58. Abrams JZ. Metzora(at) kashaleg: leprosy - challenges to authority in the Bible. Jewish Bible Quarterly. 1993;21(1):41-45.

59. Jacob JT, Franco-Paredes C. The stigmatization of leprosy in India and its impact on future approaches to elimination and control. PLoS Negl Trop Dis. 2008;2(1):e113. 


\section{Publish your work in this journal}

Psychology Research and Behavior Management is an international, peerreviewed, open access journal focusing on the science of psychology and its application in behavior management to develop improved outcomes in the clinical, educational, sports and business arenas. Specific topics covered include: Neuroscience, memory \& decision making; Behavior modification \& management; Clinical applications; Business \& sports performance management; Social and developmental studies; Animal studies. The manuscript management system is completely online and includes a quick and fair peer-review system. Visit http://www.dovepress. com/testimonials.php to read real quotes from published authors.

Submit your manuscript here: http://www.dovepress.com/psychology-research-and-behavior-management-journal 